\title{
RESTORATION OF HISTORIC BUILDINGS IN ZANZIBAR
}

\author{
John K. Makunza \\ Department of Structural and Construction Engineering, College of Engineering and \\ Technology, University of Dar es Salaam \\ P.O. Box 35131, Dar es Salaam \\ E-mail: makunzaj@gmail.com
}

\begin{abstract}
Looking at current state of most repaired historic buildings in Stone Town of Zanzibar, it is quite clear that the repair attempts made have not been very successful. Modern materials and techniques introduced in the repair works have often proven to be incompatible with the original materials causing accelerated deterioration of buildings fabric. This shows that, there is no comprehensive study undertaken so far on identifying the appropriate materials and restoration techniques. To solve this problem, a study has been made with the main objective of developing the means of restoring historic buildings by using materials existing in Stone Town of Zanzibar. The study was conducted through visual investigation and laboratory testing of materials taken from existing historical buildings and those that are currently being used for repair. Laboratory test conducted includes chemical analysis, grading, compressive strength and water absorption. The results showed some similarities in both materials, however, the combination ratios are not the same resulting into different properties. It has therefore been established that sand of the same grading pattern as the one found in the historic building mortar must be sought and utilized in making repair mortar at a ratio of 1 part lime to 3 parts sand.
\end{abstract}

Keywords: Historic building, lime, limestone, coral stones and mortar

\section{INTRODUCTION}

Zanzibar is an archipelago made up of Zanzibar and Pemba Islands. It is located in the Indian ocean, about $40 \mathrm{~km}$ from the Tanzanian mainland coast, and $6^{\circ}$ South of the Equator. Zanzibar Island shown in Figure 1, locally known as Unguja, is 97 $\mathrm{km}$ long and $32 \mathrm{~km}$ wide, occupying a total area of approximately 1683 square kilometers.

Stone Town is the old city and cultural heart of Zanzibar Town. It is a place of winding alleys, bustling bazaars, mosques and grand stone houses whose original owners vied with each other over the extravagance of their dwellings (refer
Figure 2). Stone Town contains around 1709 Stone Masonry Buildings and associated structures that have architectural styles which reflect special culture that has brought together homogenized different elements of cultures from Africa, Middle East, Far East and Europe (Mohan, 2004). Stone Town has great historical value and has become tourist attraction thus benefiting Zanzibar people in terms of culture and economy.

The buildings are up to three stories high and have massive external and internal walls. The thickness of the walls range from 500 to $1000 \mathrm{~mm}$. The walls are constructed of rubble stones randomly set 
in a thick lime based mortar similar to the historic old Boma building in Bagamoyo (Makunza, 2013). Most of these buildings are plastered and then lime-washed. Some of the walls have very shallow foundation of about $500 \mathrm{~mm}$; however, most of them don't have foundation. The mangrove poles are used to support the floors and roofs and to keep the walls upright. major materials used for walling purposes include coral limestone, lime and sand. Some upper floors are made of steel I beams and mass lime concrete. The floor slab is usually in form of bays of around $1200 \mathrm{~mm}$ wide and utilizes the arch principle in which the forces are transmitted to the beams then to the masonry walls.

Stone Town is a World Heritage; this means, it is a conserved area. One of the principles of conservation is to restore the buildings to their original status, using similar materials and design principle (Sandbhor and Botre, 2013). Looking at current state of most repaired historic buildings in Stone town it is quite clear that the repair attempts made have not been effective (see Figures 4 and 5).
Observing the facade of the historic buildings in Stone Town, Zanzibar, stone units still appear to be in good condition while mortar (joint mortar, plaster, render) present an extremely advanced deteriorated condition of the buildings as seen in Figures 4 and 5. Therefore, this shows that, there is no any comprehensive study undertaken so far on identifying the original materials used for construction and restoration techniques. Thus, there was a need to investigate on the materials used in these historic buildings so that the same type of materials and techniques would be identified and used for restoration purposes.

The main objective of carrying out the study was firstly, to seek for restoration materials which have the same structural properties as the original ones so that they provide good compatibility in the old buildings, making the buildings more durable with minimum intervention. Secondly, by matching the original materials techniques closely, the repair materials would age in a similar manner as the original ones.

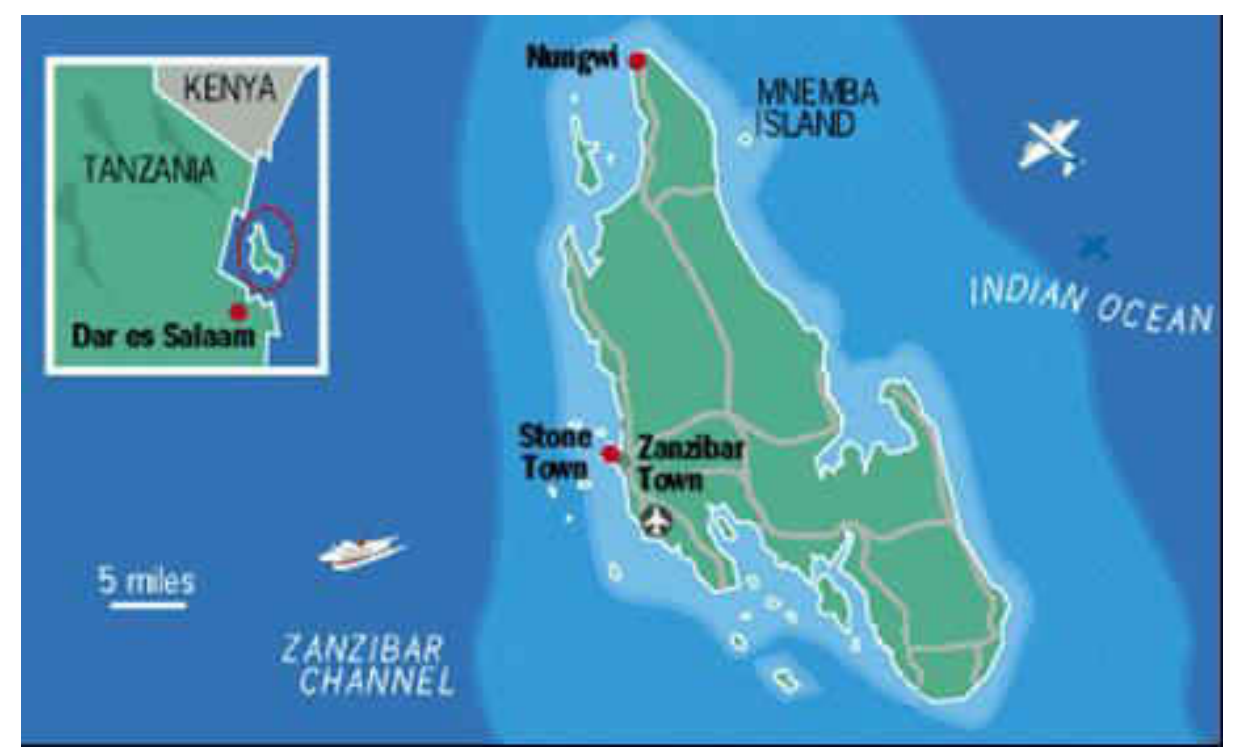

Figure 1: Zanzibar Map showing stone town area 


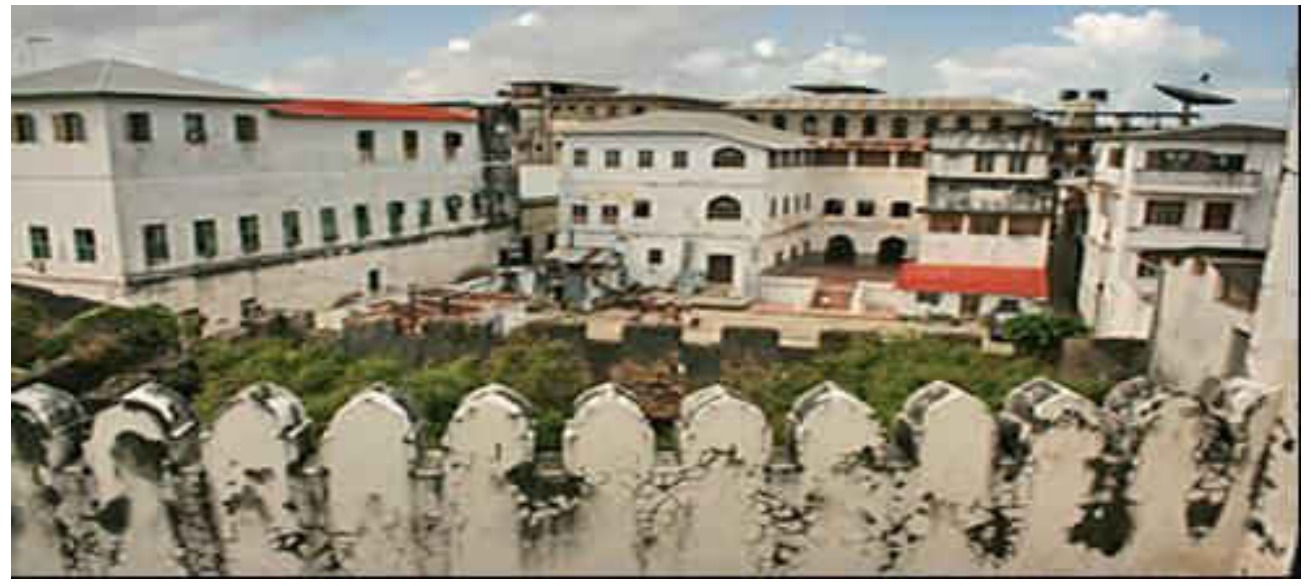

Figure 2: Historic buildings in Zanzibar

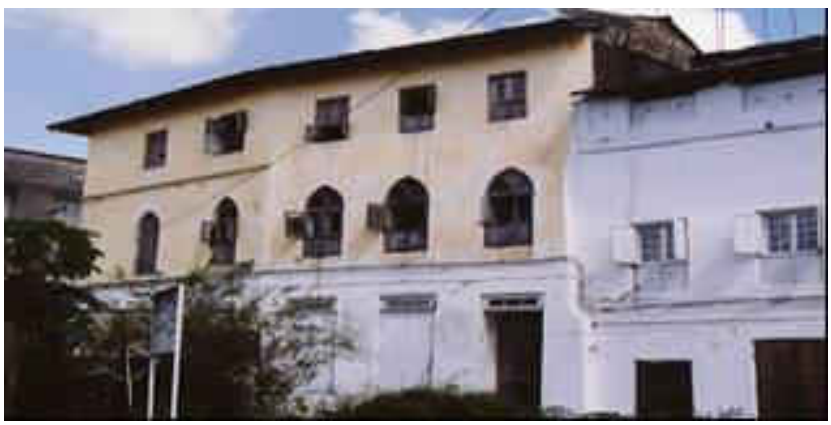

(a) Middle East design

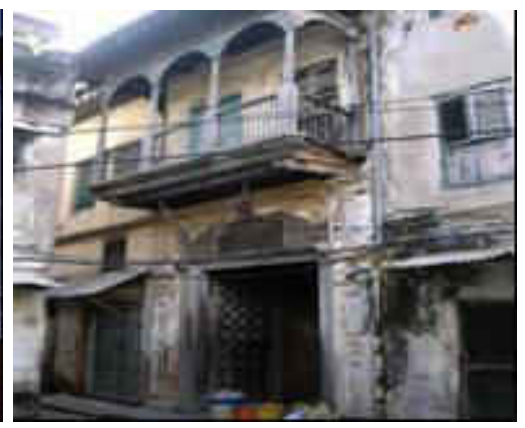

(b) Far East design

Figure 3: Designs from different parts of the world

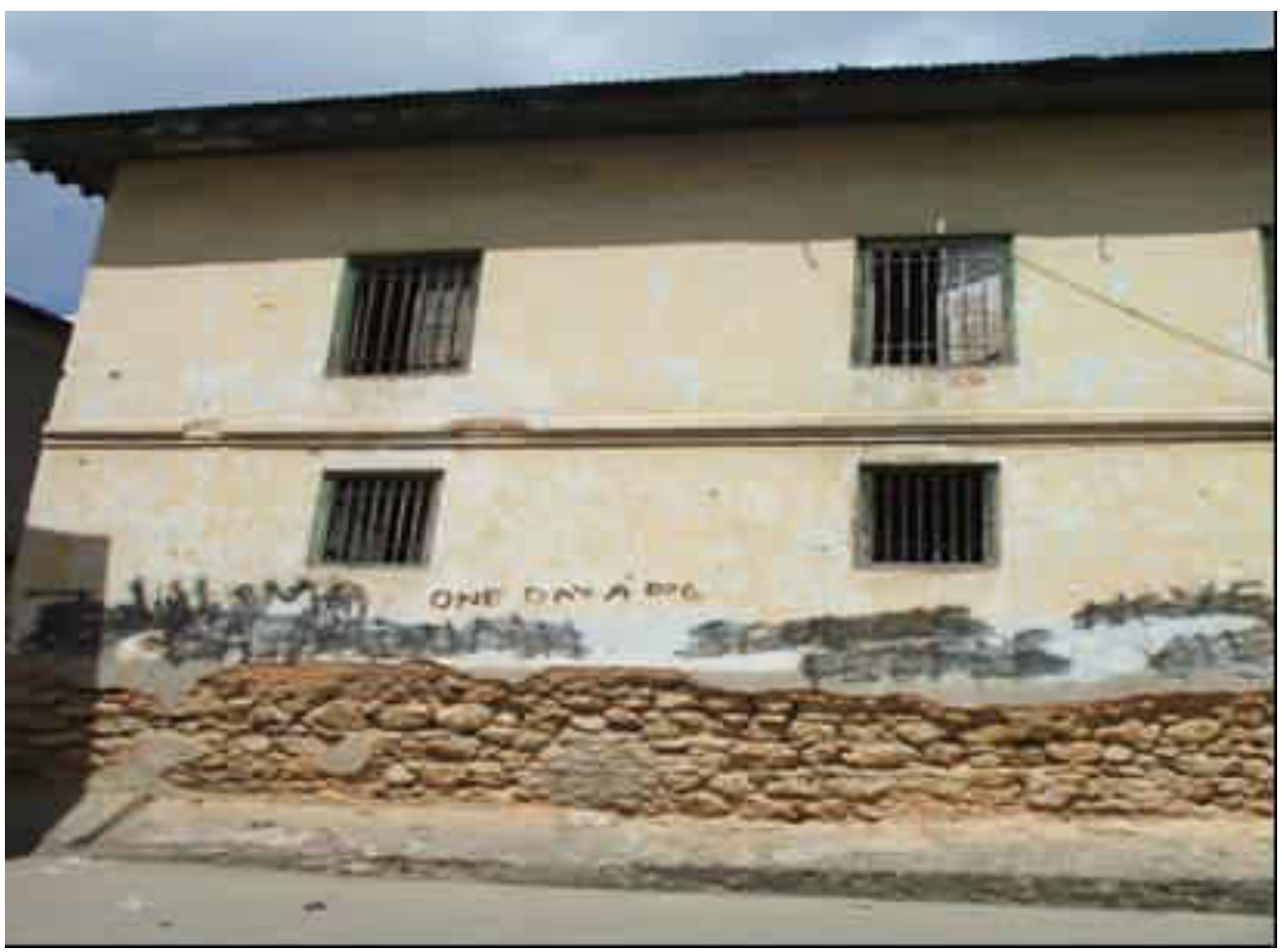

Figure 4: Recently repaired building, but with delaminated plaster 


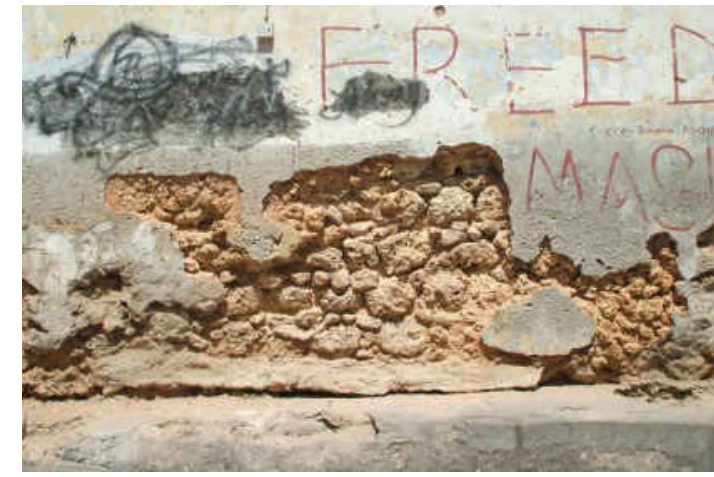

(a) Deteriorated mortar

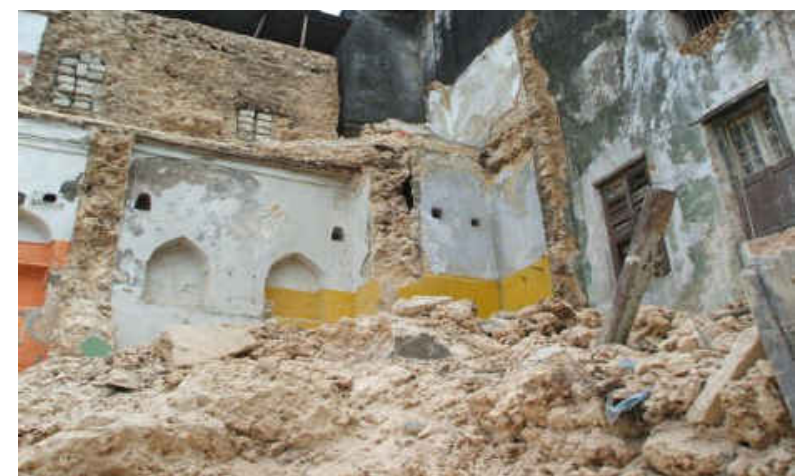

(b) Collapsed building

Figure 5: Deteriorated buildings

\section{METHODS AND MATERIALS}

The methodology adopted included both field and laboratory works, thus:

Field Work: In this category the following activities were performed:

i. Visual assessment of the old buildings, materials used for their construction and materials that are being used for restoration purposes.

ii. Sampling of materials from existing historic buildings and new materials that are currently being used for restoration like mortar, lime, soil and stones.

Laboratory work: In this case, different tests on materials were performed for different purposes as indicated below:

i. To determine chemical properties of the materials sampled from old buildings which include stones and mortar.

ii. To establish compressive strength of existing mortar and limestones.

iii. To establish compressive strength of prepared new mortar at ages of 7, 14 and 28 days.

iv. To determine compressive strength of limestone used for restoration purposes.

v. To conduct gradation test of sand taken from the existing historic buildings. vi. To conduct gradation test of sand that is currently being used for restoration purposes.

\section{Testing Programme}

The testing program encompassed field investigation of the historic buildings and parallel tests of the characteristics of hardened lime-based mortars and stones. The characterization of the Stone Town historical materials involved visual assessment, sampling and testing.

\section{i) Visual Assessment}

The first assessment carried out was visual assessment of the entire historics buildings and associated structures in Stone Town. It was then observed that all the historic buildings were massive masonry structures.

\section{ii) Sampling}

To ensure that samples taken represent materials under investigation, building and associated structures constructed between $15^{\text {th }}$ and $19^{\text {th }}$ century with lime based mortars were sampled. All samples taken were extracted using hammer and chisel.

\section{- Old Stones and Old Hardened Mortar Samples}

Samples of coral stones and hardened old mortar were taken from the historic buildings while Limestone samples were 
taken from the heaps of limestone that were awaiting to be used for restoration purposes. All samples were then sent to the Structures and Building Materials Laboratory at the University of Dar es Salaam whereby they were cut to size of $70 \times 70 \times 70 \mathrm{~mm}$ cubes. From the cubes, densities and compressive strengths were determined by performing the respective tests.

\section{- Preparation of New Mortar Samples}

The binder in the mortar mixture was commercial-dry hydrated lime powder. The type of sand used was the currently used for restoration purposes. The lime to sand ratio in these samples was $1: 3$ by volume. The dry slaked lime was soaked in water for $24 \mathrm{hrs}$ before mixing with sand so as to improve carbonation and minimize cracks. The amount of added water was adjusted in order to obtain normal consistence and good workability. Samples of $70 \times 70 \times 70 \mathrm{~mm}$ in size were cast, after hardening they were kept in normal room temperature and humidity in a water bath as shown in Figure 8.

\section{(ii) Testing}

In this category, tests were done for chemical analysis, grading of sand, water absorption (Roberto and Roberto, 2007), densities, and compressive strengths of materials as briefly described below:

\section{(a) Mineralogical (Chemical ) Analysis} The mineralogical analysis of lime mortars and stones were determined using X-ray fluorescence (XRF) machine depicted in Fig. 9. The test was done in sequence as illustrated by the flow chart.

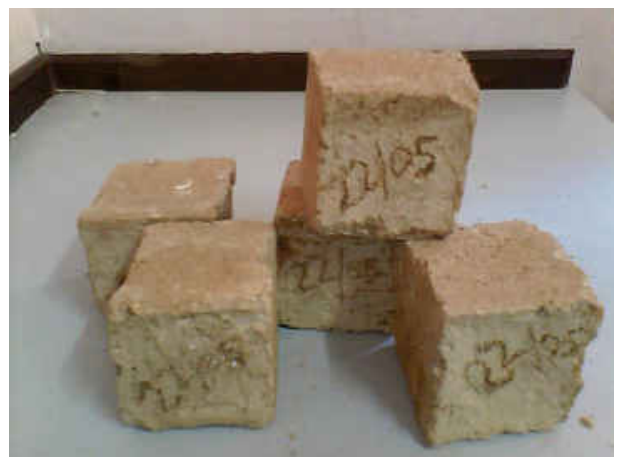

Figure 8: Cubic mortar samples

\section{RESULTS}

\section{Chemical Analysis Results}

Table 1 reports on the mineral compounds of the samples as determined from the XRF test machine. For historical mortar, the results indicate calcium oxide $(\mathrm{CaO})$ as the major compound element occupying more than $40 \%$. This phenomena is also the same for the newly prepared mortar as depicted in the same Table 1 . Test results from coral stones and limestone, have revealed that $\mathrm{CaO}$ occupies more than $50 \%$ as can be viewed in Table 2. In both type of samples; mortars and stones, it is evident that $\mathrm{CaO}$ content is the major compound occupying more than $40 \%$ for mortars and more than $50 \%$ in stones.

\section{Grading of Sand}

The grain size distribution in soil/sand is usually determined by performing Sieve Analysis Test. The significance of the test is to reveal the relative proportions of different grain particle sizes as they are distributed among certain size ranges of the soil. Both sands from historic mortar as well as from current quarry used for restoration works were sampled and tested. The obtained test results were analyzed and plotted as depicted in Figure 10. 

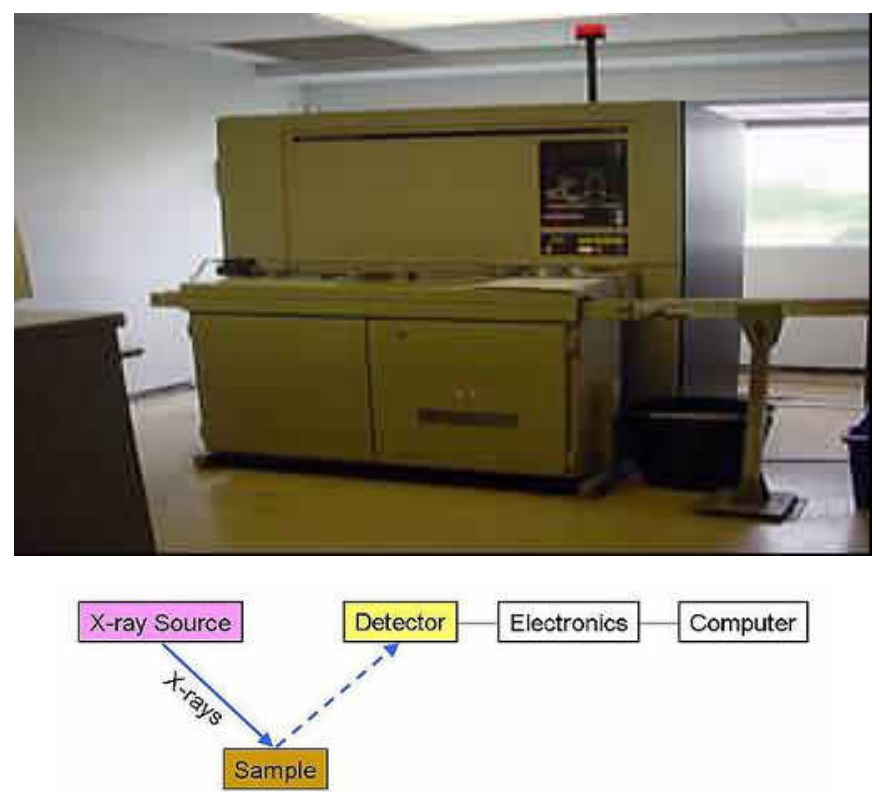

Figure 9: X-ray fluorescence spectrometer (Philips PW1606)

Table 1: Analysis of major element in Old Mortar in Historic buildings and New Mortar

\begin{tabular}{||l|l|l|l|l|l|l|l||}
\hline \hline Sample ID & $\begin{array}{l}\mathrm{MgO} \\
\%\end{array}$ & $\begin{array}{l}\mathrm{Al}_{2} \mathrm{O}_{3} \\
\%\end{array}$ & $\begin{array}{l}\mathrm{SiO}_{2} \\
\%\end{array}$ & $\begin{array}{l}\mathrm{Na}_{2} \mathrm{O} \\
\%\end{array}$ & $\begin{array}{l}\mathrm{K}_{2} \mathrm{O} \\
\%\end{array}$ & $\begin{array}{l}\mathrm{SO}_{3} \\
\%\end{array}$ & $\begin{array}{l}\mathrm{CaO} \\
\%\end{array}$ \\
\hline \hline $\begin{array}{l}\text { Historical } \\
\text { mortar }\end{array}$ & 0.72 & 5.05 & 17.2 & 0.33 & 0.91 & 0.58 & 40.45 \\
\hline $\begin{array}{l}\text { Current } \\
\text { mortar }\end{array}$ & 0.45 & 4.00 & 18.2 & 0.44 & 0.91 & 0.58 & 42.45 \\
\hline \hline $\begin{array}{l}\text { Sample ID } \\
\%\end{array}$ & $\begin{array}{l}\mathrm{TiO}_{2} \\
\%\end{array}$ & $\begin{array}{l}\mathrm{Fe}_{2} \mathrm{O}_{3} \\
\%\end{array}$ & $\begin{array}{l}\mathrm{Cl} \\
\%\end{array}$ & $\begin{array}{l}\mathrm{P}_{2} \mathrm{O}_{5} \\
\%\end{array}$ & $\begin{array}{l}\mathrm{Cr}_{2} \mathrm{O}_{3} \\
\%\end{array}$ & $\begin{array}{l}\mathrm{MnO} \\
\%\end{array}$ & $\begin{array}{l}\text { LOI } \\
\%\end{array}$ \\
\hline \hline $\begin{array}{l}\text { Historical } \\
\text { mortar }\end{array}$ & 0.22 & 0.06 & 0.23 & 0.18 & 0.04 & 0.02 & 33.43 \\
\hline $\begin{array}{l}\text { Current } \\
\text { mortar }\end{array}$ & 0.22 & 0.06 & 0.30 & 0.18 & 0.04 & 0.02 & 30.43 \\
\hline \hline
\end{tabular}

Table 2: Chemical Test Results for Coral-stones and Lime stones

\begin{tabular}{||l|l|l|l|l|l|l|l||}
\hline \hline Sample ID & $\begin{array}{l}\mathrm{MgO} \\
\%\end{array}$ & $\begin{array}{l}\mathrm{Al}_{2} \mathrm{O}_{3} \\
\%\end{array}$ & $\begin{array}{l}\mathrm{SiO}_{2} \\
\%\end{array}$ & $\begin{array}{l}\mathrm{SrO} \\
\%\end{array}$ & $\begin{array}{l}\mathrm{K}_{2} \mathrm{O} \\
\%\end{array}$ & $\begin{array}{l}\mathrm{SO}_{3} \\
\%\end{array}$ & $\begin{array}{l}\mathrm{CaO} \\
\%\end{array}$ \\
\hline \hline \hline Coral stone & 0.28 & 0.91 & 2.53 & 1.10 & 0.10 & 0.49 & 53.38 \\
\hline Lime stone & 0.40 & 0.13 & 0.40 & 0.25 & $<0.01$ & 0.13 & 54.13 \\
\hline \hline Sample ID & $\begin{array}{l}\mathrm{TiO}_{2} \\
\%\end{array}$ & $\mathrm{Fe}_{2} \mathrm{O}_{3} \%$ & $\begin{array}{l}\mathrm{Na} 2 \mathrm{O} \\
\%\end{array}$ & $\begin{array}{l}\mathrm{P}_{2} \mathrm{O}_{5} \\
\%\end{array}$ & $\begin{array}{l}\mathrm{ZrO} 2 \\
\%\end{array}$ & $\begin{array}{l}\text { LOI } \\
\%\end{array}$ & \\
\hline \hline Coral stone & 0.05 & 0.02 & 0.43 & 0.08 & 0.18 & 40.45 & 43.69 \\
\hline Lime stone & 0.02 & 0.75 & $<0.01$ & 0.10 & $<0.01$ & \multicolumn{1}{||||}{} \\
\hline \hline
\end{tabular}




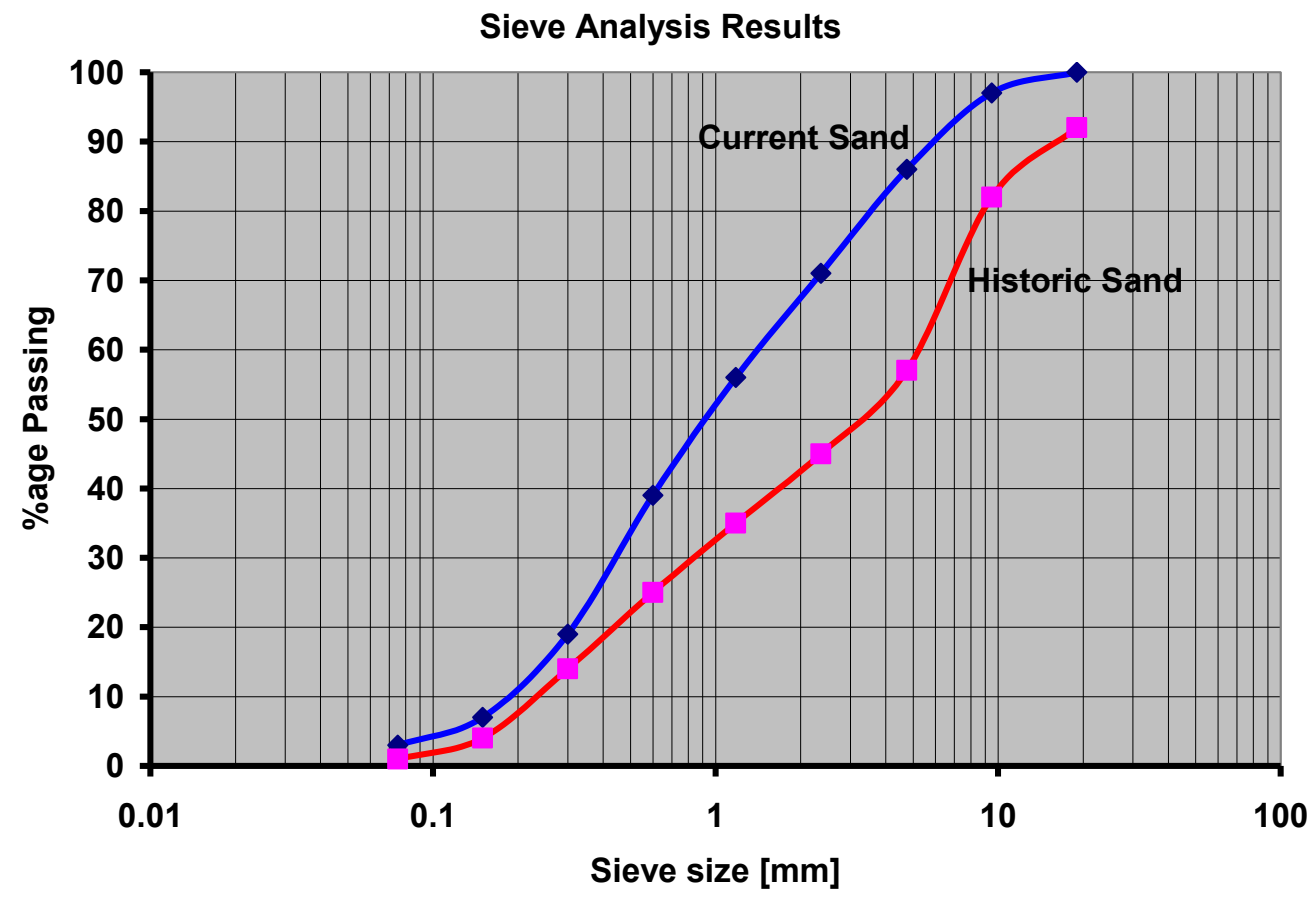

Figure 10: Grading of sand

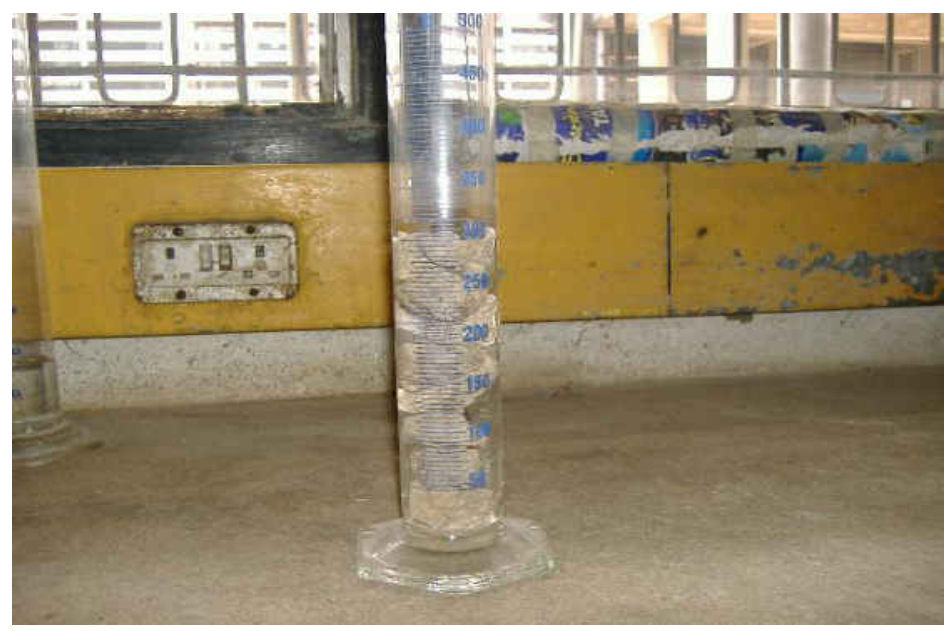

Figure 11: Water absorption test

\section{Water Absorption}

The water absorption test was undertaken in order to assess the amount of water that could be absorbed by the coral stone as well as the limestone. The process of water absorption test was involved with oven drying the samples for 24 hours, then measuring the materials weight, (W1). The samples were then immersed in tap water in a flask for 24 hours as depicted in Figure 11.

The samples were taken from water, surface dried and then weighed (W2) again. The difference between $\mathrm{W} 1$ and $\mathrm{W} 2$ was the amount of water absorbed. The amount of water absorbed was then divided by $\mathrm{W} 1$ and then multiplied by $100 \%$ leading to water absorption in 
percentage as shown in Fig. 12. The test results show that the coral stone have higher water absorption, about 3 times that of limestone. However, the absorption of both types of stones are within the specifications. It has been revealed that coral stones are more porous than limestones, a property that implies that it has high heat insulation capability, a condition suitable for tropical buildings.

Water Absorption

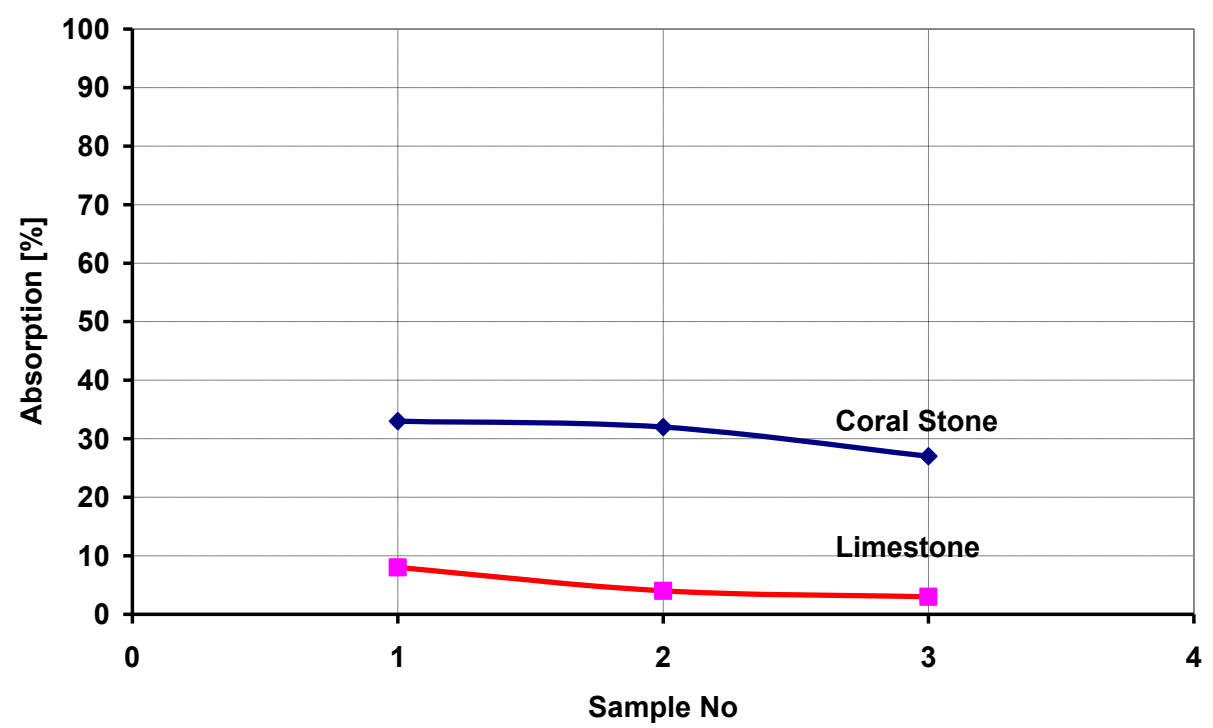

Figure 12: Water absorption of coral-stone and limestone

\section{Densities}

The densities of coral stones, limestone, old mortar and new mortar were also determined from the weights, and volumes of the specimens. Each specimen was weighted, and its volume calculated. The density was then calculated by a simple formula:

$$
\text { Density, } D=\frac{\text { Mass }}{\text { Volume }}
$$

The obtained densities are plotted in Figures 13 and 14. In Figure 13, it is revealed that the density of limestone is higher than that of coral stones, it is almost double of the later one. This big difference is attributed by the fact that coral stones are porous as revealed in the water absorption test. Such condition implies that even their respective strengths may differ by nearly the same proportion.

\subsection{Tests for Compressive Strengths}

Compressive strength of historical mortars, prepared mortar samples and stones (coral and lime stone) were determined using a universal compression machine test. The obtained results are plotted in Figures 15 and 16 , briefly discussed below:

\section{- Compressive Strength of Stones.}

Figure 15 shows the test results of compressive strengths for coral stones and limestone. From the results it is evident that the strength of limestones is more than that of coral stones by approximately twice as much. The difference in the strength is due to the fact that coral stone is light and porous in comparison with the limestone.

\section{- Compressive Strength of Mortars.}

Samples from the current mortar at the age of 14 days had an average compressive strength of only $0.30 \mathrm{~N} / \mathrm{mm}^{2}$ due to the fact that lime has slow rate of chemical reactions that lead to strength 
development. At 28 days age, the compressive strength for the new mortar as indicated in Figure 16, was found to be not more than $0.56 \mathrm{~N} / \mathbf{m m}^{2}$. This low value may be attributed by the age of the samples, since the required time for full strength development for lime material is 105 days or 3 months.

Densities of Coral stone and Limestone

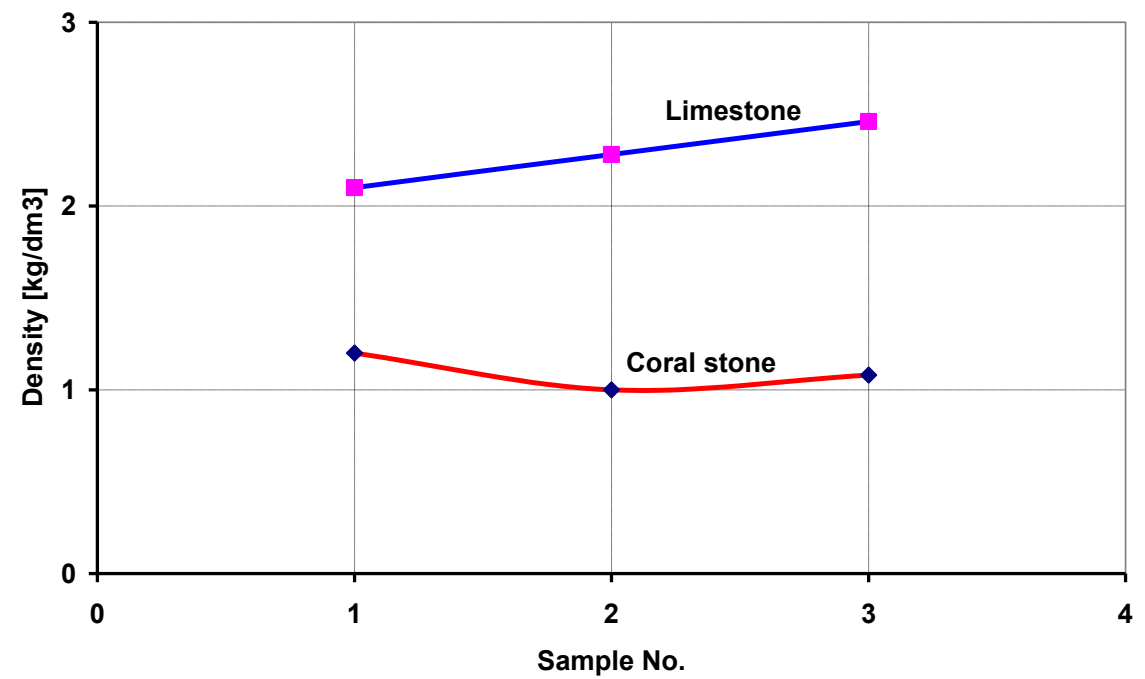

Figure 13: Densities of stones

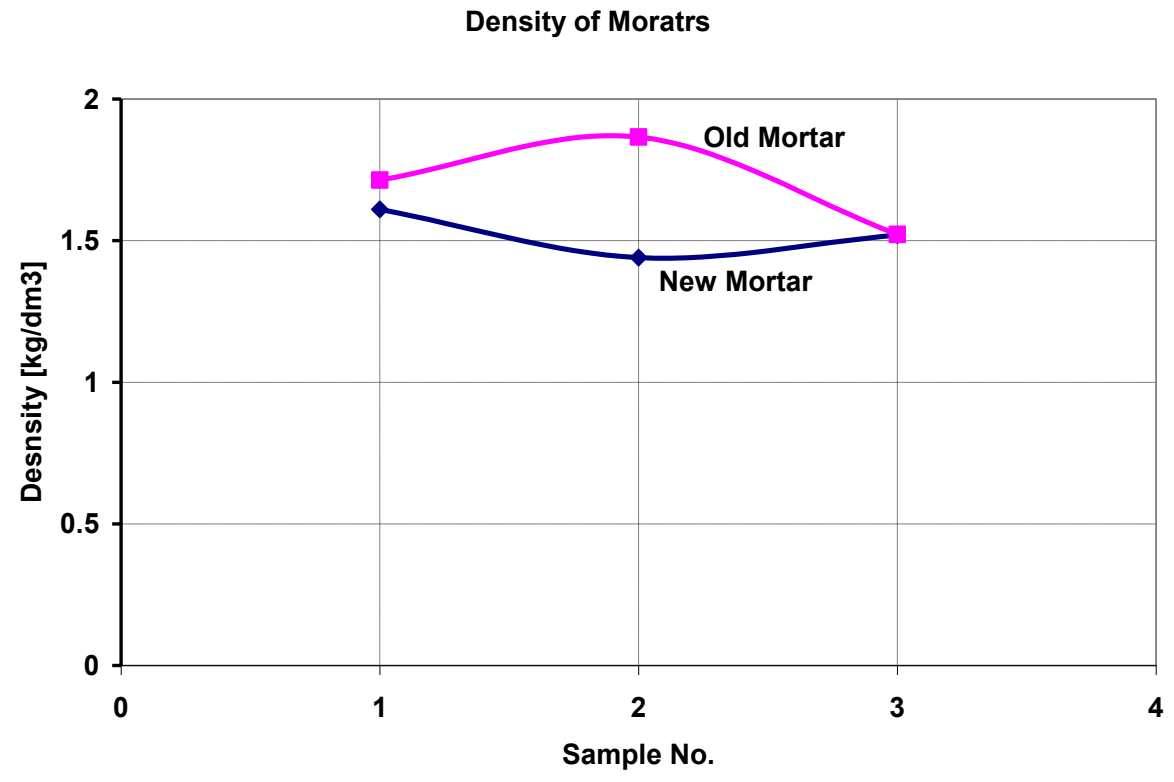

Figure 14: Density of mortars 
Compressive Strength of Stones

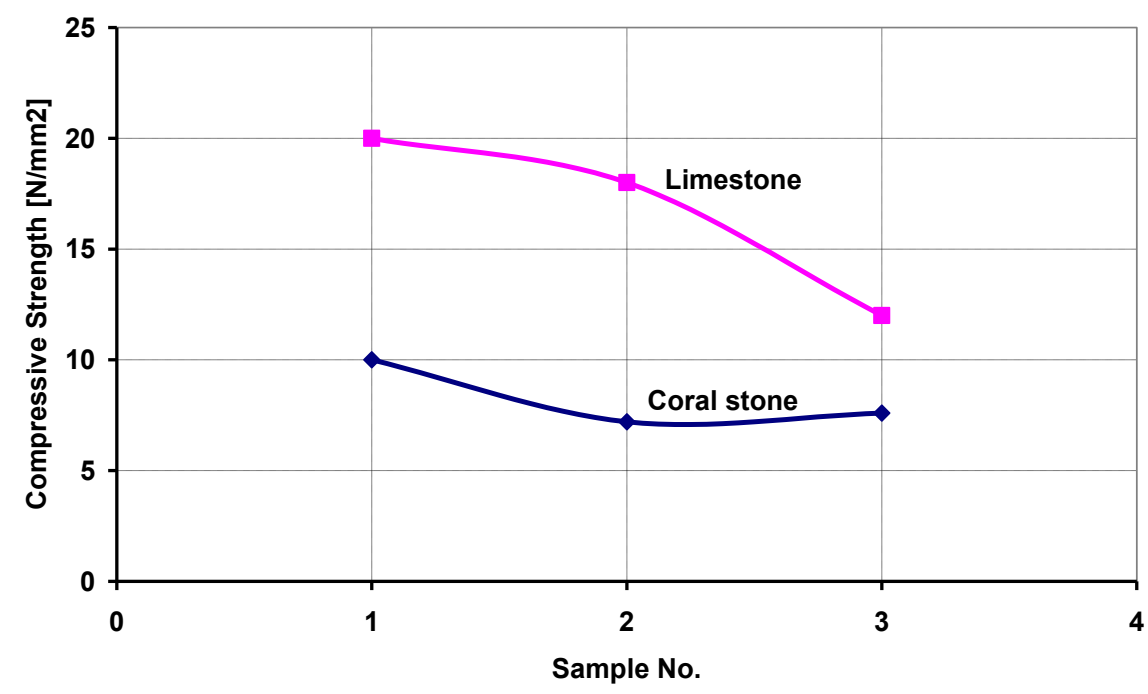

Figure 15: Compressive strength result of coral and limestone.

\section{Compressive Strength of Mortars}

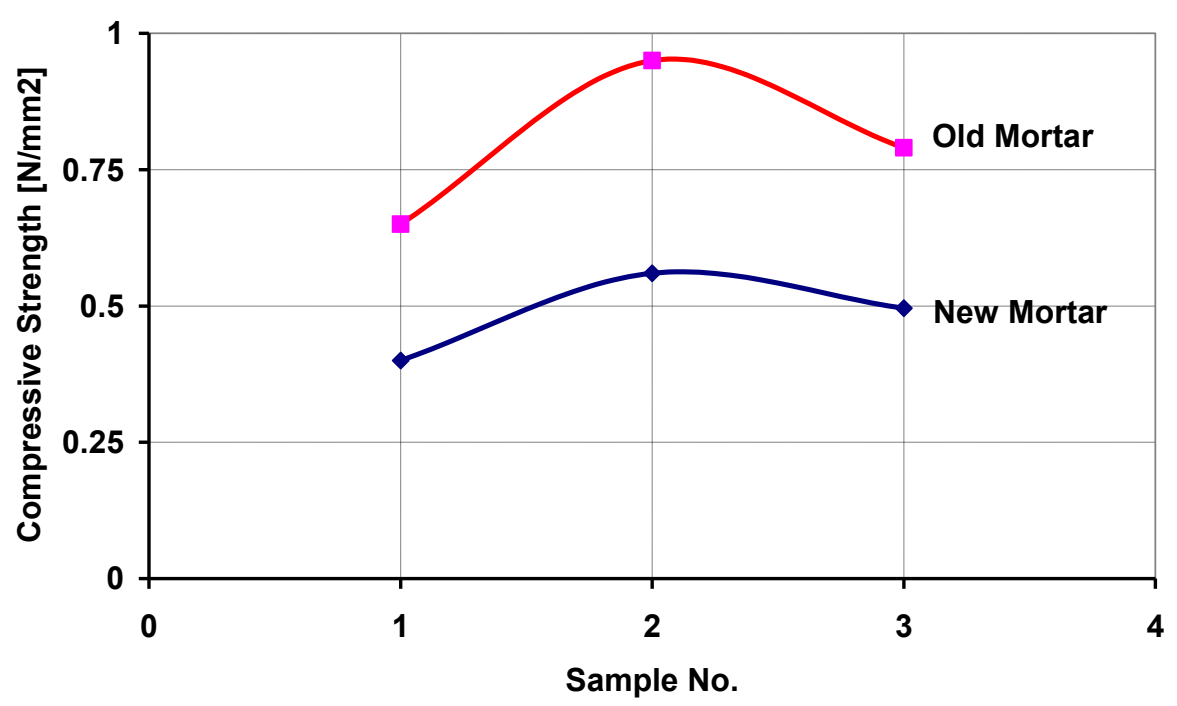

Figure 16: Compressive strength of mortars

\section{CONCLUSIONS}

Chemical properties are similar in stones and mortars that are currently used for restoration and those found in historic buildings, however, there are very small differences which do not affect the chemical properties of mortars and stones. Compressive strength values of limestone are greater than coral stone. Compressive strength of current mortar will continue to develop strength until 3 months due to slow rate of chemical reactions, however, 
it shows that there will be substantial strength closer to the historic mortar strength.

Historic mortar has shown good results in compressive strength as it varies from 0.65 up to $0.95 \mathrm{~N} / \mathrm{mm}^{2}$. Sieve analysis results show that the sands which are used in current mortar are finer than the sands which were used in the historic mortar. For the case of water absorption, coral stones absorb more water than limestones.

\section{RECOMMENDATIONS}

According to the study conducted and conclusions reached, it is recommended that for the mortar to be of high strength in current practice, it is important to search for the sand that has almost the same grading as the one which has been found in the historic buildings mortar. The sand must possess coarser particles than the one in current use which needs more lime due to having finer particles. For the correct sand grade, the appropriate ratio of lime to sand shall be 1 part lime to 3 parts sand. For stones it is recommended to use limestones for the bottom part of the building, say up to $1.00 \mathrm{~m}$ above the ground level because they are stronger than coral stones and have less water absorption. Coral stones should be used for walls above $1.00 \mathrm{~m}$ from ground level so as to improve heat insulation of the buildings due to their high porosity properties.

\section{REFERENCES}

Mohan M (2004). Historical Information System for Surveying Monuments and Spatial Data Modeling for Conservation of Cultural Heritage in Delhi-India. Workshop on Archaeological Surveys, Athens, Greece, 22-27 May 2004.

Makunza J.K. (2013). Investigations on the Availability of Construction Materials of the Same Properties as Those Found in the Old Boma Building at Bagamoyo - Tanzania for Conservation Purposes. Final Report, BICO, CoET, August 2013.

Sandbhor S. and Botre R. (2013). A Systematic Approach Towards Restoration Of Heritage Buildings- A Case Study. IJRET MAR 2013, Available at http://www.ijret.org/ ISSN: $2319-1163,2(3)$ : 229 238.

Roberto M. and Roberto S. (2007). Criteria And Experiences On Structural Rehabilitation Of Stone Masonry Buildings In Mexico City. International Journal of Architectural Heritage, 1(1): 3 28. 